\title{
Consórcio couve-coentro em cultivo orgânico e sua influência nas popu- lações de joaninhas
}

\author{
André Luis S Resende ${ }^{1 *}$; Abraão José da S Viana²; Rafael J Oliveira ${ }^{2}$; Elen de L Aguiar-Menezes ${ }^{3}$; Raul \\ de LD Ribeiro ${ }^{4}$; Marta dos SF Ricci ${ }^{3}$; José Guilherme M Guerra ${ }^{3}$ \\ ${ }^{1}$ UFRRJ, Pós-graduação em Fitotecnia, Rod. BR 465, km 07, 23890-000 Seropédica-RJ; ${ }^{2}$ UFRRJ-Instituto de Agronomia; ${ }^{3}$ Embrapa \\ Agrobiologia, C. Postal 74505, 23890-000 Seropédica-RJ; ${ }^{4}$ UFRRJ-Instituto de Agronomia, Dept ${ }^{\circ}$ Fitotecnia; *autor correspondente; \\ alsresende@yahoo.com.br
}

\section{RESUMO}

O consórcio de culturas é comumente praticado na produção de hortaliças devido a diversos benefícios econômicos. Em alguns casos, podem reduzir infestações de pragas por favorecer a conservação dos inimigos naturais nos agroecossistemas. Avaliou-se a viabilidade agronômica do consórcio de couve e coentro, sob manejo orgânico, com base em parâmetros fitotécnicos, além de sua influência sobre populações de joaninhas (Coleoptera: Coccinellidae), na comparação com os respectivos cultivos solteiros. O coentro, representando a cultura secundária, foi utilizado com a finalidade de fornecer recursos para as joaninhas. O estudo foi realizado em área do Sistema Integrado de Produção Agroecológica em Seropédica-RJ. O experimento consistiu dos consórcios: 1) couve consorciada com coentro, cujas quatro linhas de plantas foram colhidas na fase vegetativa (consórcio I), e 2) couve consorciada com coentro, cujas plantas das duas linhas internas (próximas à linha da couve) foram colhidas na fase vegetativa e as duas linhas externas foram cortadas após floração (consórcio II). Em ambos consórcios foram avaliados os parâmetros fitotécnicos da couve e do coentro na fase vegetativa (padrão comercial), enquanto que no consórcio II, também se avaliou as populações de joaninhas, por meio de coletas semanais de adultos, em comparação com a couve em cultivo solteiro. O delineamento experimental foi em blocos ao acaso com quatro repetições. $O$ coentro não interferiu na produtividade da couve consorciada e sua introdução contribuiu positivamente para a abundância e diversidade de espécies de joaninhas. O índice de equivalência de área para o consórcio I, com referência aos rendimentos de biomassa aérea fresca, foi superior em $92 \%$ em relação ao cultivo solteiro. Este resultado demonstra a viabilidade do consórcio I, no manejo orgânico adotado, para plantios de outono nas condições edafoclimáticas da Baixada Fluminense.

Palavras-chave: Brassica oleracea var. acephala, Coriandrum sativum, agricultura orgânica, eficiência agronômica, controle biológico.

\begin{abstract}
Performance of the kale-coriander intercropping in organic cultivation and its influence on the populations of ladybeetles

Intercropping is commonly practiced in the production of vegetable crops due to diverse economic benefits. In some cases, it may decrease the infestations of pests by favoring the conservation of the natural enemies in the agroecosystems. This study aimed to evaluate the agronomical viability of the kale and coriander intercropping, under organic management, based on phytotechnical parameters, and its influence on the populations of ladybeetles (Coleoptera: Coccinellidae) in comparison to respective sole crops. Coriander, representing the secondary crop, was used aiming to provide resources to ladybeetles. The study was carried out in area of the Sistema Integrado de Produção Agroecológica, Seropédica county, State of Rio de Janeiro. The experiment consisted of two types of intercropping: 1) kale intercropped with coriander, whose four lines of plants were harvested at the vegetative phase (intercropping I), and 2) kale intercropped with coriander, whose plants of the two internal lines (near to the line of kale) were harvested at the vegetable phase, and the two external lines were cut after blossom (intercropping II). In both intercropping the phytotechnical parameters of the kale and the coriander at the vegetative phase (commercial standard) were evaluated, while in the intercropping II, the populations of ladybeetles were also evaluated by weekly samples of adults, in comparison to kale sole crop. The experimental design was of randomized blocks with four replicates. Coriander did not interfere in the productivity of the kale intercropped and its introduction contributed positively to the abundance and the species diversity of ladybeetles. The land equivalent ratio for the intercropping I, taking into account the yield of fresh aerial biomass, was superior in $92 \%$ in relation to kale sole crop. This result demonstrates the viability of the intercropping I, in the organic management adopted, for cultivation of autumn in the edaphoclimatic conditions of the Baixada Fluminense region.
\end{abstract}

Keywords: Brassica oleracea var. acephala, Coriandrum sativum, organic agriculture, agronomic efficiency, biological control.

(Recebido para publicação em 26 de fevereiro de 2009; aceito em 12 de janeiro de 2010) (Received on February 26, 2009; accepted on January 12, 2010)

$\mathrm{O}$ consórcio de culturas é um importante componente dos sistemas agrícolas sustentáveis, nos quais se incluem os orgânicos. É uma prática agrícola bastante comum no cultivo de hortaliças em pequenas unidades de produção de regiões tropicais, sobretudo aquelas de base familiar (Montezano \& Peil, 2006). Entre os benefícios dos consórcios estão a otimização do aproveitamento da terra, água, insumos agrícolas e mão-de-obra, além da contribuição para estabilização da atividade rural, assegurando colheitas escalonadas e possibilitando renda adicional para o produtor (Cecílio Filho \& May, 2002; Montezano \& Peil, 2006).

$\mathrm{O}$ aumento da produção por unidade de área cultivada é uma das razões mais importante para o emprego de consórcios de culturas (Montezano \& 
Peil, 2006). Todavia, de modo geral, o sistema consorciado não infere no uso de tecnologias que busquem máxima produtividade. Há consórcios nos quais as interações biológicas representam serviços ecológicos de importância acentuada, dentre eles a redução do nível de dano ocasionado por insetos-pragas, através de estímulos aos inimigos naturais, tais como as joaninhas predadoras (Santos, 1998; Patt et al., 1997; Altieri et al., 2003). Por exemplo, em estudo sobre consórcios de berinjela (Solanum melongena L.) com duas apiáceas (coentro (Coriandrum sativum L.) ou endro (Anethum graveolens L.) no controle do inseto-praga Leptinotarsa decemlineata (Say) (Coleoptera: Chrysomelidae), Patt et al. (1997) observaram nos consórcios maior abundância e diversidade de espécies de joaninhas predadoras, principalmente Coleomegilla maculata DeGeer, Coccinella septempunctata L., Harmonia axyridis (Pallas), Hippodamia parenthesis (Say), Hippodamia variegata Goeze e Propylea quatuordecimpunctata L., comparativamente ao cultivo solteiro da berinjela, bem como observaram o aumento do consumo de massas de ovos do inseto-praga pelas joaninhas.

Esses estímulos são, geralmente, proporcionados pela presença da planta "companheira" (cultura secundária) no consórcio e referem-se ao fato dessas plantas provocarem alterações microclimáticas favoráveis e/ou proverem abrigo e/ou recursos nutricionais suplementares, como pólen, néctar e presas ou hospedeiros alternativos, aos inimigos naturais, proporcionando a conservação desses agentes de controle biológico no agroecossistema (Altieri et al., 2003; Wackers et al., 2005; Montezano \& Peil, 2006). Vários estudos conduzidos em sua maioria nos EUA, na Europa e na Austrália mostraram que espécies de plantas da família Apiaceae podem fornecer recursos que garantem a sobrevivência e/ou reprodução de inimigos naturais e que, portanto, poderiam compor consórcios culturais com o propósito de fornecer esse serviço ecológico (Bugg \& Wilson, 1989; Patt et al., 1997).

Contudo, a eficiência agronômica dos sistemas consorciados depende da complementaridade espacial e temporal entre culturas, sendo necessário minimizar a competição entre as espécies e cultivares envolvidas (Montezano \& Peil, 2006). Resultados positivos, em termos de produtividade, conferem aos consortes a condição de plantas "companheiras" (Kuepper \& Dodson, 2001; Montezano \& Peil, 2006).

$\mathrm{O}$ índice de equivalência de área (IEA) tem sido usado com freqüência como indicador da eficiência dos consórcios. Assim, o IEA estima a área física requerida aos cultivos solteiros para que se obtenha produção equivalente à do sistema consorciado. Quando o IEA é maior que 1,0 fica demonstrada a viabilidade técnica do manejo estabelecido para o consórcio (Vandermeer, 1989; Montezano \& Peil, 2006).

De acordo com Montezano \& Peil (2006), o consórcio de hortaliças, embora praticado com freqüência, é ainda pouco pesquisado. Segundo estes mesmos autores, as cultivares de hortaliças são selecionadas visando o monocultivo, e torna imprevisível o comportamento dos genótipos quando em cultivo consorciado, portanto, indicando a conveniência da experimentação em nível regional.

Nenhum registro específico sobre o desempenho agronômico do consórcio entre couve (Brassica oleracea L. var. acephala D.C.) e coentro (Coriandrum sativum L.) foi encontrado. Tivelli et al. (2006) avaliaram o consórcio de couve com alface (Lactuca sativa L.), constatando aumentos significativos na produtividade da couve, na qualidade da alface e na eficiência do uso da terra, em relação aos respectivos cultivos solteiros. Pesquisas sobre consórcio de diversas hortaliças como o coentro têm apresentado resultados promissores, incluindo cenoura (Dacus carota L.) (Freitas et al., 2004), alface (Freitas et al., 2004; Oliveira et al., 2005), cebolinha (Allium fistulosum L.) (Zárate et al., 2005), taro [Colocasia esculenta (L.) Schott] (Zárate et al., 2007a) e rabanete (Raphanus sativus L.) (Grangeiro et al., 2008).

O presente estudo teve o objetivo de avaliar a viabilidade técnica do consórcio de couve e coentro, em sistema orgânico de produção, nas condições edafoclimáticas da Baixada Fluminense, com base em parâmetros fitotécnicos, assim como sua influencia sobre populações de joaninhas (Coleoptera: Coccinellidae).

\section{MATERIAL E MÉTODOS}

O estudo foi conduzido no período de abril a outubro de 2007 em área do Sistema Integrado de Produção Agroecológica (SIPA). O SIPA representa um projeto de pesquisa em agricultura orgânica, caracterizado pelo cultivo diversificado de hortaliças, fruteiras e cereais integrado à produção animal. Está localizado no município de Seropédica (22 $46^{\prime} \mathrm{S}, 43^{\circ} 41^{\prime} \mathrm{W}$ e $33 \mathrm{~m}$ de altitude), Região Metropolitana do estado do Rio de Janeiro (Neves et al., 2005).

O solo da área experimental é classificado como Argissolo VermelhoAmarelo, cuja análise, realizada na fase de pré-plantio, à profundidade de 0-20 $\mathrm{cm}$, revelou: $\mathrm{pH}$ em água $=6,7 ; \mathrm{Al}^{+++}=$ $0,0 \mathrm{cmol}_{\mathrm{c}} \mathrm{dm}^{-3} ; \mathrm{Ca}^{++}=3,5 \mathrm{cmol}_{\mathrm{c}} \mathrm{dm}^{-3}$; $\mathrm{Mg}^{++}=1,3 \mathrm{cmol}_{\mathrm{c}} \mathrm{dm}^{-3} ; \mathrm{K}^{+}=517,5 \mathrm{cmol}_{\mathrm{c}}$ $\mathrm{dm}^{-3}$ e $\mathrm{P}$ disponível $=179,7 \mathrm{mg} \mathrm{dm}^{-3}$. A adubação orgânica consistiu da incorporação de $100 \mathrm{~kg}$ de $\mathrm{N} \mathrm{ha}^{-1}$ aos canteiros por ocasião da semeadura do coentro e de $50 \mathrm{~kg}$ de $\mathrm{N} \mathrm{ha}^{-1}$ mensalmente, ao redor das plantas de couve, até o final do ciclo produtivo. As fontes de adubo foram, respectivamente, o esterco de bovino curtido (pré-plantio) e a torta de mamona em cobertura.

Adotou-se o delineamento experimental de blocos ao acaso, com quatro repetições. Os tratamentos foram: 1) couve consorciada com coentro, sendo este colhido aos 55 dias após a semeadura, ainda em fase vegetativa (consórcio I); 2) couve consorciada com coentro, cujas plantas correspondentes às duas linhas interiores (mais próximas à linha de plantio da couve) foram colhidas aos 55 dias após a semeadura e às duas linhas externas mantidas até o final da fase de floração (consórcio II); 3) coentro em cultivo solteiro; e 4) couve em cultivo solteiro.

Foram utilizadas a cultivar HeviCrop de couve (Brassica oleracea var. acephala D.C.) e a cultivar Asteca de coentro (Coriandrum sativum L.). O coentro foi utilizado como cultura secundária por possuir nectários florais 
(Diederichsen, 1996), objetivando suplementar recursos alimentares para as joaninhas. As mudas de couve foram produzidas em bandejas de poliestireno expandido, abastecidas com substrato orgânico. O coentro foi semeado diretamente nos canteiros, sete dias antecedendo o transplantio das mudas de couve.

A couve foi cultivada no espaçamento padrão de $1,0 \times 0,5 \mathrm{~m}$, enquanto o coentro foi semeado em linhas distanciadas de 0,2 m entre si, conservando-se 20 plantas por metro linear após o desbaste. Esses espaçamentos foram empregados tanto nos cultivos solteiros de cada espécie quanto nos consórcios entre elas. As parcelas experimentais ocuparam $6,0 \mathrm{~m}^{2}(6,0 \times 1,0 \mathrm{~m})$, sendo compostas por 11 plantas de couve dispostas em linha única e/ou 480 plantas de coentro dispostas em quatro linhas, independentemente do tratamento (consórcio ou cultivo solteiro).

A cada colheita semanal de couve foram aferidos: número de folhas de padrão comercial por planta; área foliar específica (relação entre a área foliar e a biomassa seca das folhas); índice de área foliar (IAF = razão entre área foliar colhida e unidade de área cultivada) e produtividade (biomassa fresca das folhas de padrão comercial por metro quadrado de área cultivada). A área foliar foi determinada pelo método de referência, usando o aparelho digital integrador (LI-COR, modelo LI 3100). No total, foram realizadas 21 colheitas semanais de couve, com início aos 40 dias após o transplantio das mudas.

Com respeito aos parâmetros fitotécnicos do coentro, foram avaliados: altura das plantas aos 50 dias após semeadura, rendimento em biomassa de parte aérea (fresca e seca), número de molhos de $100 \mathrm{~g}$ por unidade de área cultivada $\left(\mathrm{m}^{2}\right)$ e número de hastes por planta (obtido pela média de 80 indivíduos por parcela), os quais foram determinados aos 55 dias após semeadura.

A avaliação da eficiência agronômica do consórcio I foi feita por meio do cálculo do índice de equivalência de área (IEA), com base nas produções de biomassa da parte aérea fresca da couve (produtividade total) e do coentro, sendo este último colhido no padrão comercial (aos 55 dias a contar da semeadura). Foi utilizada a seguinte equação (Vandermeer, 1989): IEA $=\left(\mathrm{I}_{\text {couve }} \mathrm{S}^{-1}{ }_{\text {couve }}\right)+\left(\mathrm{I}_{\text {coentro }}\right.$ $\mathrm{S}^{-1}$ coentro $)$, onde: I e $\mathrm{S}=$ produtividade correspondente a cada cultura no cultivo consorciado e no cultivo solteiro, respectivamente.

Para aferir a diversidade de espécies e os níveis populacionais de joaninhas predadoras, foram executadas coletas desses insetos três vezes por semana nas plantas de couve e coentro no consórcio II e de couve no cultivo solteiro. Nessas plantas também foi observada a presença ou a ausência de pulgões. Os adultos de joaninhas foram removidos manualmente ou com auxílio de aspirador bucal, durante períodos de 30 minutos para cada parcela experimental, seguindo metodologia proposta por Michels Junior et al. (1996). As joaninhas foram acondicionadas em copos plásticos transparentes $(250 \mathrm{ml})$, tamponados com tela de organza para permitir ventilação, sendo as amostras transportadas ao laboratório para contagem e identificação taxonômica. A freqüência relativa das espécies de joaninhas foi estabelecida pela seguinte equação: $F=n \times 100 / N$, em que $n=$ número de adultos de determinada espécie de joaninha e $\mathrm{N}=$ número total de adultos, equivalendo a todas as espécies de joaninhas coletadas.

Nos dados obtidos, as pressuposições de normalidade e homogeneidade de variâncias foram obtidas e análises univariada de variância foram realizadas através do programa SAEG 9.0. Diferenças significativas entre tratamentos foram estabelecidas pelo teste $\mathrm{F}$ ( $\mathrm{P}=$ $0,05)$ e as médias comparadas pelo teste de Tukey $(\mathrm{p}=0,05)$.

\section{RESULTADOS E DISCUSSÃO}

O consórcio com a couve não influenciou a maioria dos parâmetros fitotécnicos relativos ao coentro (Tabela 1). Houve diferença significativa apenas para altura da planta, superior no cultivo consorciado. Esse mesmo resultado foi observado em consórcios de coentro com outras espécies de hortaliças, os quais induziram maior porte da planta de coentro, caracterizando que houve competição por luz (Zárate et al., 2005;
Zárate et al., 2007a; Grangeiro et al., 2008).

Diferindo dos resultados obtidos no presente estudo, Zárate et al. (2007a,b) e Grangeiro et al. (2008) observaram que o rendimento em massa fresca de parte aérea do coentro foi maior no cultivo solteiro, porém, as cultivares usadas por esses autores foram outras (Português e Verdão). Em experimento de avaliação de consórcios entre alface e coentro, conduzido por Oliveira et al. (2005) em Mossoró, estado do Rio Grande do Norte, a cultivar de coentro Asteca em cultivo solteiro alcançou rendimento em massa aérea fresca de $1,992 \mathrm{~kg} \mathrm{~m}^{-2}$, assim ultrapassando o valor médio obtido no presente estudo para a mesma cultivar. Tal variação pode ser atribuída a diferenças edafoclimáticas e de práticas culturais empregadas.

Todavia, nos experimentos de Oliveira et al. (2005), quando em cultivo consorciado com alface, os valores referentes a número de molhos de 100 $\mathrm{g} \mathrm{m}^{-2}$, número de haste planta $^{-1}$ e rendimento em massa fresca da parte aérea para a cultivar Asteca foram mais baixos do que no consórcio com a couve aqui relatado (Tabela 1 ).

Quanto à couve, o consórcio com o coentro não afetou o número de folhas por planta em qualquer das 21 colheitas semanais realizadas. Na maioria dessas colheitas, o consórcio também não mostrou influencia sobre a área foliar específica da couve.

Efeito significativo foi apenas constatado na sétima e na nona colheitas (Tabela 2 ), onde se observou na couve no cultivo solteiro e no consórcio I redução de área foliar específica, em comparação ao consórcio II.

O índice de área foliar (IAF) da couve também diferiu significativamente em função dos sistemas de cultivo, em apenas duas das colheitas efetuadas (Tabela 2). Na terceira colheita, o cultivo solteiro da couve resultou em valores significativamente mais altos de IAF, mas não diferindo do consórcio II. Na décima colheita, contrariamente à terceira, neste tipo de consórcio, observou-se valores de IAF inferiores aos dos dois outros tratamentos.

Em 14 das 21 colheitas de couve, não houve diferença significativa na 
Tabela 1. Parâmetros fitotécnicos do coentro, sob manejo orgânico, em cultivo solteiro e no consórcio com couve (phytotechnical parameters of coriander, under organic management, in sole crop and intercropped with kale). Seropédica, SIPA, 2007.

\begin{tabular}{|c|c|c|c|c|c|}
\hline \multirow[t]{2}{*}{ Sistemas de cultivos } & \multirow{2}{*}{$\begin{array}{l}\text { Altura da planta } \\
\text { aos } 50 \text { dias }(\mathrm{cm})\end{array}$} & $\begin{array}{l}\text { Biomassa aérea } \\
\text { fresca }\left(\mathrm{kg} \mathrm{m}^{-2}\right)\end{array}$ & $\begin{array}{l}\text { Biomassa aérea } \\
\text { seca }\left(\mathrm{kg} \mathrm{m}^{-2}\right)\end{array}$ & $\begin{array}{l}N^{0} \text { de hastes } \\
\text { planta }^{-1}\end{array}$ & $\begin{array}{l}N^{0} \text { de molhos } \\
(100 \mathrm{~g}) \mathrm{m}^{-2}\end{array}$ \\
\hline & & \multicolumn{4}{|c|}{ Aos 55 dias } \\
\hline Consórcio couve-coentro & $37,57 \mathrm{a}$ & $1,981 \mathrm{a}$ & $0,194 \mathrm{a}$ & $13,00 \mathrm{a}$ & $19,81 \mathrm{a}$ \\
\hline Cultivo solteiro de coentro & $34,67 \mathrm{~b}$ & $1,835 \mathrm{a}$ & $0,203 \mathrm{a}$ & $13,28 \mathrm{a}$ & $18,35 \mathrm{a}$ \\
\hline $\mathrm{CV}(\%)$ & 4,00 & 17,50 & 20,86 & 7,53 & 9,13 \\
\hline
\end{tabular}

Valores representam médias de quatro repetições; Médias seguidas da mesma letra nas colunas não diferem pelo teste $\mathrm{F}$ ao nível de $5 \%$ de probabilidade (values represent means of four replicates; Means followed by the same letter in the columns do not differ by $\mathrm{F}$ test at $5 \%$ probability level).

produtividade da couve entre tratamentos, demonstrando que ambos os tipos de consórcio couve $\mathrm{x}$ coentro pouco interferiram na produtividade da cultura principal. A produtividade da couve em cultivo solteiro diferiu significativamente de apenas um dos consórcios com referência à terça parte das colheitas semanais (Tabela 2).

No consórcio I, em que as quatro linhas de coentro foram colhidas de uma única vez e coincidindo com a segunda colheita da couve, constatou-se uma queda significativa na produtividade da brássica nas duas colheitas seguintes, em comparação ao cultivo solteiro (Tabela
2). No entanto, da quinta colheita em diante, a produtividade da couve consorciada equiparou-se à de seu cultivo solteiro, com exceção da $15^{\mathrm{a}}$ colheita.

No consórcio II, em que as duas linhas externas de coentro foram mantidas até o final da fase de floração, a produtividade da couve foi significativamente menor em relação aos outros dois tratamentos na primeira colheita $\mathrm{e}$ novamente entre as $12^{\mathrm{a}}$ e $15^{\mathrm{a}}$ colheitas (Tabela 2). Tal efeito possivelmente correlacionou-se à retirada do coentro florido, que coincidiu com a data da 12 a colheita.

Em termos de produtividade total da couve, quando o coentro foi colhido aos 55 dias de idade (consórcio I), não se observou interferência na comparação com o cultivo solteiro, ocorrendo o contrário com o consórcio II, em que se constatou queda de produtividade da couve (Tabela 2).

O índice de equivalência de área (IEA) referente ao consórcio I atingiu o valor de 1,92. Isto significa que os cultivos solteiros de couve e coentro precisariam de $92 \%$ a mais de área ocupada com os consórcios para alcançar rendimento equivalente. Oliveira et al. (2005) registraram valores de IEA, relacionados a consórcios de duas cultivares

Tabela 2. Produtividade, área foliar específica (AFE) e índice de área foliar (IAF) de colheitas da couve, com diferenças significativas, obtidos no cultivo solteiro e nos cultivos consorciados com o coentro, sob manejo orgânico (productivity, specific leaf area (SLA) and index of leaf area (ILA) of harvests of kale, with significant differences, obtained in the sole crop and the intercroppings with coriander, under organic management). Seropédica, SIPA, 2007.

\begin{tabular}{|c|c|c|c|c|}
\hline \multirow[b]{2}{*}{ Colheitas } & \multicolumn{3}{|c|}{ Produtividade $\left(\mathrm{kg} \mathrm{m}^{-2}\right)$} & \multirow[b]{2}{*}{ CV $(\%)$} \\
\hline & $\begin{array}{c}\text { Coentro colhido na fase } \\
\text { vegetativa }^{1}\end{array}$ & $\begin{array}{l}\text { Coentro mantido até o final da } \\
\text { fase da floraçã }{ }^{2}\end{array}$ & Cultivo solteiro & \\
\hline $1^{\mathrm{a}}$ & $0,6317 \mathrm{a}^{3}$ & $0,4728 b$ & $0,6965 \mathrm{a}$ & 5,29 \\
\hline $3^{\mathrm{a}}$ & $0,2171 b$ & $0,2503 \mathrm{ab}$ & $0,3228 \mathrm{a}$ & 17,24 \\
\hline $4^{\mathrm{a}}$ & $0,2013 b$ & $0,2416 \mathrm{ab}$ & $0,3226 \mathrm{a}$ & 19,37 \\
\hline $12^{\underline{a}}$ & $0,2383 a$ & $0,1487 \mathrm{~b}$ & $0,3029 a$ & 15,46 \\
\hline $13^{\mathrm{a}}$ & $0,2711 \mathrm{ab}$ & $0,2109 b$ & $0,3495 \mathrm{a}$ & 16,72 \\
\hline $14^{\mathrm{a}}$ & $0,2159 \mathrm{ab}$ & $0,1781 b$ & $0,2553 \mathrm{a}$ & 13,83 \\
\hline $15^{\mathrm{a}}$ & $0,2404 b$ & $0,2334 b$ & $0,2760 \mathrm{a}$ & 6,30 \\
\hline Total & $5,503 \mathrm{ab}$ & $5,017 \mathrm{~b}$ & $6,4960 a$ & 34,71 \\
\hline \multicolumn{5}{|c|}{ AFE $\left(\mathrm{cm}^{2}\right.$ de folhas $\mathrm{g}^{-1}$ massa aérea seca) } \\
\hline $7 \underline{a}$ & $149 \mathrm{ab}$ & $160 \mathrm{a}$ & $135 b$ & 5,91 \\
\hline $99^{a}$ & $140 \mathrm{~b}$ & $167 \mathrm{a}$ & $127 \mathrm{~b}$ & 4,77 \\
\hline \multicolumn{5}{|c|}{ IAF $\left(\mathrm{cm}^{2}\right.$ de folhas $\mathrm{m}^{-2}$ de área cultivada $)$} \\
\hline $3^{\mathrm{a}}$ & $1004 b$ & 1081ab & $1349 a$ & 13,62 \\
\hline $10^{\mathrm{a}}$ & $1163 a$ & $944 b$ & $1206 a$ & 8,09 \\
\hline
\end{tabular}

${ }^{1}$ Consorcio I (Intercropping I); ${ }^{2}$ Consorcio II (Intercropping II); ${ }^{3}$ Valores representam médias de quatro repetições; Médias seguidas da mesma letra nas linhas não diferem pelo teste de Tukey ao nível de 5\% de probabilidade; Total de 21 colheitas (values represent means of four replications; Means followed by the same letter in the rows do not differ by Tukey test at 5\% probability level; Total of 21 harvests). 
Tabela 3. Diversidade de espécies e densidades populacionais de adultos de joaninhas (Coleoptera: Coccinellidae) coletados durante todo o período do experimento, no consórcio couve $\mathrm{x}$ coentro e no cultivo solteiro de couve, sob manejo orgânico (species diversity and adult population densities of ladybeetles (Coleoptera: Coccinellidae) collected during all period of the experiment, in kale and coriander intercropping and in sole crop of kale, under organic management). Seropédica, SIPA, 2007.

\begin{tabular}{|c|c|c|c|c|}
\hline \multirow{2}{*}{ Espécies } & \multicolumn{2}{|c|}{$\begin{array}{c}\text { Consórcio couve } x \\
\text { coentro }\end{array}$} & \multicolumn{2}{|c|}{$\begin{array}{c}\text { Cultivo solteiro de } \\
\text { couve }\end{array}$} \\
\hline & $\begin{array}{l}\text { № total de } \\
\text { indivíduos }\end{array}$ & $\mathbf{F}^{1}$ & $\begin{array}{l}\text { № total de } \\
\text { indivíduos }\end{array}$ & $\mathbf{F}$ \\
\hline Brachiacantha sp. & 1 & 0,6 & 0 & 0,0 \\
\hline Cycloneda sanguinea (L.) & 99 & 59,6 & 7 & 58,3 \\
\hline Eriopis connexa Germar & 32 & 19,3 & 1 & 8,3 \\
\hline Harmonia axyridis (Pallas) & 3 & 1,8 & 0 & 0,0 \\
\hline Hippodamia convergens Guérin & 5 & 3,0 & 0 & 0,0 \\
\hline Hyperaspis festiva Mulsant & 13 & 7,8 & 3 & 25,0 \\
\hline Hyperaspis notata Mulsant & 2 & 1,2 & 0 & 0,0 \\
\hline Scymnus (Pullus) sp. & 9 & 5,4 & 1 & 8,3 \\
\hline Nephus sp. & 1 & 0,6 & 0 & 0,0 \\
\hline Zagreus bimaculosus Mulsant & 1 & 0,6 & 0 & 0,0 \\
\hline Riqueza de espécies² & \multicolumn{2}{|l|}{10} & \multicolumn{2}{|l|}{4} \\
\hline № total de indivíduos & \multicolumn{2}{|c|}{$166 \mathrm{a}$} & \multicolumn{2}{|c|}{$12 \mathrm{~b}$} \\
\hline № médio de indivíduos coleta ${ }^{-1}$ & \multicolumn{2}{|c|}{$11,07 \mathrm{a}^{3}$} & \multicolumn{2}{|c|}{$0,8 \mathrm{~b}$} \\
\hline
\end{tabular}

$\mathrm{CV}(\%)=37,42$

${ }^{1} \mathrm{~F}=$ Freqüência relativa de espécies de joaninhas (Relative frequency of ladybeetle species); ${ }^{2}$ Número total de espécies coletadas; ${ }^{3}$ Valores seguidos da mesma letra nas linhas não diferem entre si pelo teste $\mathrm{F}$ ao nível de $5 \%$ de probabilidade (values followed by the same letter in the rows do not differ by $\mathrm{F}$ test at $5 \%$ probability level).

de alface e de cinco cultivares coentro, variando de 1,42 a 3,21, sendo que para coentro cv. Asteca, o valor de IEA para consórcio com alface Babá de Verão foi superior ao obtido para o consórcio I, o qual, por sua vez, foi inferior ao IEA do consórcio com a alface Tainá. Valores de IEA também superiores a 1,0 foram obtidos em consórcios de coentro com outras espécies de hortaliças, como cenoura (Freitas et al., 2004), cebolinha (Zárate et al., 2005), taro (Zárate et al., 2007a) e rabanete (Grangeiro et al., 2008), mas que ficaram abaixo do IEA obtido com o consórcio I. Portanto, no presente estudo, o consórcio couve $\mathrm{x}$ coentro mostrou-se efetivo, conforme postulado por Vandermeer (1989), bem como foi coerente com o princípio da "produção competitiva", o qual estabelece que "duas culturas consorciadas só irão produzir mais do que os respectivos cultivos solteiros se a competição mútua for suficientemente fraca" (Santos, 1998). borado com a ausência de infestação das plantas por pulgões, visto que a maioria das espécies de joaninhas coletadas é afidófaga (Michaud, 1998; Resende et al., 2006, 2007; Weeden et al., 2008). Hyperapis notata Mulsant e Zagreus bimaculosus Mulsant constituíram as exceções porque são consideradas coccidófagas (predadoras de cochonilhas) (Wolff et al., 2004), embora Resende et al. (2007) já tenham observado larvas de H. notata predando pulgões (Lipaphis pseudobrassicae Davis) em couve.

As populações de adultos de joaninhas no consórcio couve $\mathrm{x}$ coentro foram numericamente superiores às encontradas no cultivo solteiro de couve. A presença do coentro junto à couve, na forma de consórcio em faixas, aumentou tanto a abundância quanto a riqueza de espécies de joaninhas (Tabela 3). Patt et al. (1997), ao estudarem a influência do consórcio de berinjela com o coentro sobre populações de joaninhas, reportaram resultados análogos, também constatando número significativamente maior de indivíduos e de espécies desses insetos predadores no cultivo consorciado do que no cultivo solteiro de berinjela.

No presente estudo, o estímulo às populações de joaninhas no consórcio, principalmente à época da floração do coentro, provavelmente ocorreu porque a apiácea contribuiu como local adicional de abrigo para larvas, pupas e adultos desses predadores, além de prover sítios alternativos para oviposição, acasalamento e alimentação dos mesmos. Além de se alimentarem das presas, as joaninhas predadoras necessitam de recursos nutricionais além das presas, como pólen e néctar, os quais são capazes de garantir a sobrevivência dos adultos e sustentar o metabolismo e o desenvolvimento gamético de certas espécies (Wackers et al., 2005). Isto provavelmente justifica a alta freqüência de visitação das joaninhas às inflorescências do coentro, observada na área experimental. Patt et al. (1997) também assinalaram a freqüente visitação de joaninhas às inflorescências de coentro, à semelhança do aqui relatado. Ademais, no final da fase de floração, o coentro foi infestado por pulgões, os quais serviram de alimento para as joaninhas.

Assim, o arranjo espacial de uma 
linha central de couve e quatro linhas paralelas de coentro, mostra-se agronomicamente viável com base nos valores referentes aos índices de equivalência de área cultivada, e quando o coentro é manejado colhendo as duas linhas centrais aos 55 dias e as demais deixadas para florir estimula de modo expressivo a abundância e a diversidade de espécies de joaninhas predadoras, criando condições para o controle biológico natural.

O consórcio entre couve (cv. HeviCrop) e coentro (cv. Asteca), sob manejo orgânico e no arranjo espacial adotado mostrou-se viável, baseando-se no índice de equivalência de área cultivada, e o coentro em floração beneficia as populações de joaninhas predadoras, aumentando sua diversidade e abundância na área de cultivo.

\section{AGRADECIMENTOS}

À CAPES e à FAPERJ, respectivamente, pela concessão de bolsa de mestrado ao primeiro autor e de iniciação científica ao terceiro autor deste artigo.

\section{REFERÊNCIAS}

ALTIERI MA; SILVA EN; NICHOLLS CI. 2003. $O$ papel da biodiversidade no manejo de pragas. Ribeirão Preto: Holos. 226p.

BUGG RL; WILSON T. 1989. Ammi visnaga (L.) Lamark (Apiaceae): associated beneficial insects and implications for biological control, with emphasis on the bell-pepper agroecosystem. Biological Agriculture and Horticulture 6: 241-268.

CECÍLIOFILHOAB; MAYA. 2002. Produtividade das culturas de alface e rabanete em função da época de estabelecimento do consórcio. Horticultura Brasileira 20: 501-504.

DIEDERICHSENA. 1996. Coriander (Coriandrum sativum $L$.); promoting the conservation and use of underutilized and neglected crops. 3. Rome: Institute of Plant Genetics and Crop Plant Research, Gartensleben/ International Plant Genetic Resources Institute. 82p.
FREITAS KKC; NEGREIROS MZ; BEZERRA NETO F; AZEVEDO CMSB; OLIVEIRAEQ; BARROS JÚNIOR AP. 2004. Uso de efluente e água de rio no desempenho agroeconômico de cenoura, alface e coentro em associação. Caatinga 17: 98-104.

GABRYS B; TJALLINGII WF. 2002. The role of sinigrin in host plant recognition by aphids during initial plant penetration. Entomologia Experimentalis et Applicata 104: 89-93.

GRANGEIRO LC; NEGREIROS MZ; SANTOS AP; COSTA LM; SILVA ARC; LUCENA RRM. 2008. Crescimento e produtividade de coentro e rabanete em função da época de estabelecimento do consórcio. Ciência e Agrotecnologia 32: 55-60.

KUEPPER G; DODSON M. 2001. Companion planting: basic concepts \& resources. Fayetteville: Appropriate Technology Transfer for Rural Areas. 13p. Disponível em: http:// www.attra.org/attra-pub/complant.html. Acessado em 21 de novembro de 2008.

MICHAUD JP. 1998. A review of the literature on Toxoptera citricida (Kirkaldy) (Homoptera: Aphididae). Florida Entomologist 81: 37-61.

MICHELS JRGJ; ELLIOTT NC; ROMERO RL; JOHNSONTD. 1996. Sampling aphidophagous Coccinellidae in grain sorghum. Southwestern Entomologist 21: 237-246.

MONTEZANO EM; PEIL RMN. 2006. Sistema de consórcio na produção de hortaliças. Revista Brasileira de Agrociência 12: 129-132.

NEVES MCP; GUERRA JGM; CARVALHO SR; RIBEIRO RLD; ALMEIDA DL. 2005. Sistema integrado de produção agroecológica ou Fazendinha Agroecológica Km 47. In: AQUINOAM;ASSIS RL. (eds). Agroecologia: princípios e técnicas para uma agricultura orgânica sustentável. Brasília: Embrapa Informação Tecnológica. p. 147-172.

OLIVEIRA EQ; BEZERRA NETO FB; NEGREIROS M.; BARROS JÚNIOR AP; FREITAS KKC; SILVEIRA LM; LIMA JSS. 2005. Produção e valor agroeconômico no consórcio entre cultivares de coentro e de alface. Horticultura Brasileira 23: 285-289.

PATT JM; HAMILTON GC; LASHOMB JH. 1997. Impact of strip insectary intercropping with flowers on conservation biological control of the Colorado potato beetle. Advances Horticultural Science 11: 175-181.

RESENDE ALS; SILVA EE; GUERRA JGM; AGUIAR-MENEZES EL. 2007. Ocorrência de insetos predadores de pulgões em cultivo orgânico de couve em sistema solteiro e consorciado com adubos verdes. Seropédica, RJ: Embrapa Agrobiologia. 6p. (Comunicado
Técnico, 101).

RESENDE ALS; SILVA EE; SILVA VB; RIBEIRO RLD; GUERRA JGM; AGUIARMENEZES EL. 2006. Primeiro registro de Lipaphis pseudobrassicae Davis (Hemiptera: Aphididae) e sua associação com insetos predadores, parasitóides e formigas em couve (Cruciferae) no Brasil. Neotropical Entomology 4: 551-555.

SANTOS RHS. 1998. Interações interespecificas em consórcios de olerícolas. Viçosa: UFV. 129p. (Tese doutorado).

TIVELLI SW; TRANI PE; PURQUEIRO LF; MOREIRA SR. 2006. Consórcio de couve de folha e alface: produtividade e análise econômica. In: CONGRESSO BRASILEIRO DE OLERICULTURA, 46, Goiânia. Anais... Goiânia: SBO (CD-ROM).

VANDERMEER J.H. 1989. The ecology of intercropping. Cambridge: Cambridge University Press, 1989. 237p.

WACKERS FL; VAN RIJN, PCJ; BRUIN J. 2005. Plant-provided food for carnivorous insects: a protective mutualism and its applications. New York: Cambridge University Press. 356 p.

WEEDEN CR; SHELTON AM; HOFFMANN MP. 2008. Biological control: a guide to natural enemies in North America. Cornell University, Ithaca, NY. Disponível em http:// www.nysaes.cornell.edu/ent/biocontrol/ predators/predtoc.html. Acessado em 20 de novembro de 2008.

WOLFF VRS; PULZ CE; SILVA DC; MEZZOMO JB; PRADE CA. 2004. Inimigos naturais associados à Diaspididae (Hemiptera, Sternorrhyncha), ocorrentes em Citrus sinensis (Linnaeus) Osbeck, no Rio Grande do Sul, Brasil: I - Joaninhas e fungos entomopatogênicos. Arquivos do Instituto Biológico 71: 355-361.

ZÁRATE NAH; VIEIRA MC; HELMICH M; CHIQUITO EG; QUEVEDO LF; SOARES EM. 2007a. Produção e renda bruta da cultura do taro, em cultivo solteiro e consorciado com as culturas da salsa e do coentro. Acta Scientiarum Online, Agronomy 29: 83-89.

ZÁRATE NAH; VIEIRA MC; ONO FB; SOUZA CM. 2005. Produção e renda bruta de cebolinha e de coentro, em cultivo solteiro e consorciado. Semina: Ciências Agrárias 26: 149-154.

ZÁRATE NAH; VIEIRA MC; PONTIM BCA; FIGUEIREDO PG; QUEVEDO LF; ALMEIDA SO. 2007b. Produção e renda bruta de mandioquinha-salsa, solteira e consorciada com cenoura e coentro. Acta Scientiarum Online, Agronomy 29: 549-553. 